\title{
Innovative architectural and structural design to preserve historical centers
}

\author{
D. Félix \& A. Feio \\ University Lusíada, CITAD, Vila Nova Famalicão, Portugal
}

J. M. Branco

University of Minho, ISISE, Guimarães, Portugal

José S. Machado

LNEC, Portugal

\begin{abstract}
Historical centers are important elements of our cities, representing their history and evolution. Many cities are facing the problem of having several vacant and degraded buildings needing intervention to avoid collapses. Also several examples of unforeseen events, like earthquakes, tsunamis, floods, etc., have severely damaged important historical cities. Beyond the risk of losing built heritage, these buildings represent public danger for citizens. Thus, in post-disaster scenarios it is urgent to protect historical buildings in order to prevent the propagation of damages.

This paper presents a first efficiency assessment of using wood based systems in buildings needing urgent consolidation or damaged after disasters. Being light, easy to handle and install, as well as providing the sufficient load carrying to prevent the evolution of the damage and losses, wood and wood-based elements can be associated in different arrangements providing quick construction systems for the consolidation of damaged constructions.
\end{abstract}

\section{INTRODUCTION}

Historical centers are extremely important elements of cultural heritage, since they report and maintain alive the history and memory of a city. The preservation of buildings and ancient cores to our days allows maintaining the culture of a certain city, its habits and traditions, providing a sense of continuity, belonging and identity within the citizens.

Throughout the history, some unforeseen events have severely damaged the built environment. In Lorca (2011), an earthquake triggered the collapse of various buildings and caused severe damages to several others, driving the need for urgent intervention in order to prevent irreversible consequences. This situation is very similar to what happened after the earthquakes in Elazig, Turkey (2010), and L'Aquila, Italy (2009). In Lisbon (1988), a fire destructed various buildings in Chiado, an emblematic area of the city, which due to its severe consequences, the works of reconstruction and conservation lasted over than 20 years. In situations like those, immediate and efficient interventions are imperative to avoid the increase of damages. Thus, it is imperative to implement measures that allow fast and effective solutions to protect and consolidate affected buildings, as well as to assure minimum standards in terms of social needs.

Wood and wood-based construction systems allow solutions that are fast to build or assemble, easy to transport and available in almost areas of the globe. In spite of the lack of basis to develop construction solutions using wood that can be incorporated in historical centers after disasters, or to improve their behavior against those events, the properties described above suggest that their potential can be proposed as an innovative solution. 


\subsection{Wood and wood-based products sector: European reality}

Wood and wood-based products are one of the main sources of sustainable and renewable resources at European level, represented 1,1\% of the Gross Domestic Product (GDP) in 2000 (European Forest Sector - UNECE, 2005). They are also an important ecologic alternative, mainly due to their recycling potential and also to the recycling possibilities of wood waste, this way reducing the risk over the sustainability of forest resources.

The future competitiveness of forest products has been threatened by the growing competition of the low-cost products suppliers that have lead to a drop in prices. Due to that, during the last decades wood industry has developed and implemented solutions based on wood products or wood composites as alternatives to the common solid wood solutions.

The support to use Engineering Wood Products (EWP) on the rehabilitation of existing buildings should take into account the need to satisfy the actors' expectations. At this level, the development of global solutions has an important role. There is a search for solutions based on prefabricated elements (kits) ready to assemble, typified and that fulfill the requirements of the Construction Products Directive (CPD). At the same time, the users' satisfaction and concerns about comfort (acoustic, thermal), functionality, safety and health, as well as issues related to the protection of cultural heritage (maintenance of architectural identity and qualities, preservation of materials' characteristics, etc.) should be considered.

This way, after the identification of certain pathologies is possible to typify pattern-solutions for several scales of intervention, precisely to repair and consolidate the structural elements, or to create solutions that allow the working of crucial activities in post-disaster scenarios (Cruz \& Pequeno, 2008).

These solutions present various levels of development and several aspects should be considered to assure the durability of the structure and construction details, allowing solutions to adapt to new exigencies, considering issues such as thermal and acoustic insulation, as well as protection against fires. These solutions also have to attend to requisites such as specific weight (solutions of easy application in situ and that introduce light additional loads), performance in longterm, easy utilization, non-specialized man labor, and possibility of reutilization.

\subsection{Progress in relation to the state of knowledge}

The publication in 1988 of the Construction Products Directive (CPD - 89/106/CEE) and the Biocides Directive (98/8/CE), the publication and application of several European Norms (EU), as well as other international norms have brought out new challenges for wood sector, namely for the one directly related with the construction industry. Since that, a great effort has been done to promote and certify wood and wood-based products.

The recent research projects in wood and wood-based products have usually been concerned about behavior issues (mainly structural: deformation, fluency phenomena, etc.) and proprieties characterization (quality control and pre-normative research: bonding problems, flexion resistance, non-destructive essays, etc.). However, there is a gap in terms of basis to develop construction solutions using wood that can be incorporated in rehabilitation of ancient buildings or integrated in urban rehabilitation after disasters.

The development of new solutions for the construction market based on EWP, especially with wood composites, has grown over the last decades, although it faces the problem of lack of skilled labor. These solutions have to compete with conventional systems placed on the market, including all the elements and information needed (plus application rules) to implement the solution, and at the same time answering to all the requirements of construction industry.

Thus, despite new regulations and the great competition from conventional products and solutions not based on wood, to get in a new sector such as the rehabilitation, whether at building or urban scale, it implies new developments and research lines. At the same time, the dissemination of these activities has to be rapid and timely. The markets' search for ready-to-use construction solutions and the challenges related to their utilization in old buildings, especially in terms of connections between the new solutions and the existing construction, must be faced.

The new solutions must be concerned with the development of lower impact systems, considering fire protection, thermal and acoustic performance, an also energy saving. The lack of this kind of solutions has facilitated the way heritage buildings have been rehabilitated, often chang- 
ing wood elements for other materials. Nevertheless, this approach is not according to the actual principles for conservation and maintenance of built heritage, since it does not follow essential standards to assure the preservation of architectural and cultural values (ICOMOS, 2004).

\section{SITUATION AFTER A DISASTER}

The huge degradation of a significant number of buildings in historical centers increases the insecurity risk and reduces their resistance in unforeseen events. Combining this reality with some characteristics of historical centers, namely the high-density building and irregularity of plans, plots, and roads, it is predictable that a post-disaster scenario will become critical. The possibility of damages, such as partial or global collapse of buildings, short-cuts and explosions that can lead to fires, and streets blocked by waste and wreckage from multiple origins, is an extremely realistic scenario.

In these situations, the intervention is urgent in order to reestablish people's security, and simultaneously protect cultural objects, so as to restore the natural balance of the affected communities. The intervention has to be immediate since the first 48 hours following a disaster are very important to avoid irremediable losses to cultural heritage sites (Jha et al., 2010). Avoiding the damages increase or buildings collapses, requires urgent securing operations, namely provisional works and structures that make damaged buildings temporarily safe until permanent solutions are studied, developed and implemented (Grimaz, 2011). On the other hand, pre-disaster works of prevention, reparation, consolidation and rehabilitation, assume crucial role to defend heritage buildings and historical centers against natural disasters.

\subsection{Lack of solutions}

The wood and wood-based products sector associated to building industry faces also the challenge of an attitude changing: supplying a product necessarily means supplying structural solutions. Throughout the Europe, great investments are being done in construction sector for the renovation and rehabilitation of built heritage. In this emerging market, the consumption of wood and wood-based products is clearly inferior compared to the consumption of other materials (from non-renewable and unsustainable sources).

In these scenarios, the construction market seems to be incapable to implement solutions that respond quickly and effectively. Its conservative profile often rejects new solutions that are technically more efficient, preferring to use consolidated techniques although outdated and below of the desirable objectives. Moreover, those solutions are frequently incompatible with the new ways of rehabilitation and construction, as well as neglect the maintenance of the architectural proprieties, causing severe effects in old buildings.

This lack of responses and solutions is one of the recognized reasons for the abandonment of historical centers. As an alternative, sometimes users' make the interventions that they consider necessary, which most of the times are inadequate and inappropriate for the cultural and heritage value conservation. Both these situations increase buildings' vulnerabilities and weaken their resistance to disasters, this way enlarging the risk of loses and damages.

\section{WOOD AND WOOD-BASED SYSTEMS}

Wood and wood-based products represent an important ecologic alternative, through the recycling possibilities of wood and wood-waste, as well as due to the lower $\mathrm{CO}_{2}$ emission. With the objective to enlarge the competitiveness against new low-cost products, wood industry introduced wood-based products as alternative to solid wood solutions. These solutions enable extremely more competitive prices, and also simplify the material's transport and manipulation.

However, the consumption of wood and wood-based products is largely lower compared with the consumption of non-renewal and unsustainable materials, in spite of most the old buildings being built with wood systems.

The few available systems have some proprieties that make them able to be introduced on the rehabilitation and reconstruction of historical buildings. They are based mainly on light and 
small elements that do not overcharge the existing structures, allowing simple and easy manipulation or installation. On the other hand, they are extremely rapid to build or assemble, as well as easily transportable and available in most regions of the globe. In addition, wood and woodbased products have an excellent behavior against seismic phenomena and fire action. This is also true for their thermal and acoustic performance, issues of increasingly importance for buildings' quality evaluation. In the same way, wood and wood-based products can be used structurally, as a covering, or as a final product (products that do not need finishing works), allowing a wide range of possibilities.

Complementing these qualities, wood construction systems have good behavior against some natural disasters. Particularly wood structures, have performed relatively well during events such as earthquakes and regular winds (Lindt, 2008).

In history, one of the most notable examples of reconstruction using wood after an earthquake were the works to rebuild Lisbon downtown after the earthquake, tsunami and fires of 1 November 1755 (Alexander, 2004), through the Pombalina construction technique. The solution is well known by their wooden frame called gaiola, a system that has flexibility enough to resist an earthquake, dissipating the energy transmitted by horizontal actions without substantial damage on the whole structure. This construction system had excellent quality in architectural and structural terms for that age, being an engineering forefront work (Ramos \& Lourenço, 2000).

\section{CASE STUDIES}

Taking advantage of these potentials, the use of EWP may have a crucial role and the development of solutions with some global character assumptions has an increased importance. Solutions based on Kit systems, which means developed with prefabricated elements ready to be assemble and typified, can be innovative products with technological and sustainable character for post-disaster situations in historical centers. Despite being sometimes considered inadequate to be used in post-disaster construction systems, prefabrication has potentials that well applied can significantly improve reconstruction after disasters (Davidson et al., 2008, Garofalo \& Hill, 2008).

The Kit concept is already well established in lightweight-construction wood solutions and other systems (see European Technical Approval Guides - ETAGs at www.eota.com). In this concept not only the wood elements are separately studied (screws, connectors, glues, etc.), but also the whole system is analyzed, assuring the elemental requirements defined by the Construction Products Directive, and also national or local regulations.

\subsection{Preservation solutions}

Historical buildings often have several wood construction elements and their protection is crucial, since most of them have essential structural functions for the building safety. Some studies have presented examples of simple preservation and consolidation actions with wood solutions that do not cause changes on the original structure nor on the architectural characteristics of the building. A study conducted by Modena et al. (2010) demonstrates how simple actions are able to increase the wooden floors stiffening with controlled interventions that do not modify the overall behavior and seismic force redistribution. Providing double planking in orthogonal direction or with $45^{\circ}$ of rotation, using tongue-and-groove joints and nails or screw as connectors, and also inserting diagonal wooden, can be some possible strengthening methodologies.

Wood and wood-based systems also allow preservation actions for more critical and complex situations. The architecture office naumann.architektur has developed a design solution for a ruin dated to 1780 that was severally damaged during the Second World War. Following the concept of "a house inside a house", the solution consists in introducing a wood-construction inside the existing stone construction. The entire solution is developed with plywood of $39 \mathrm{~mm}$ and does not have contact with the existing structure, only protecting it with a new zinc-roof. The new structure was partially constructed and transported to the local, where it was quickly assembled, see Fig. 1. 

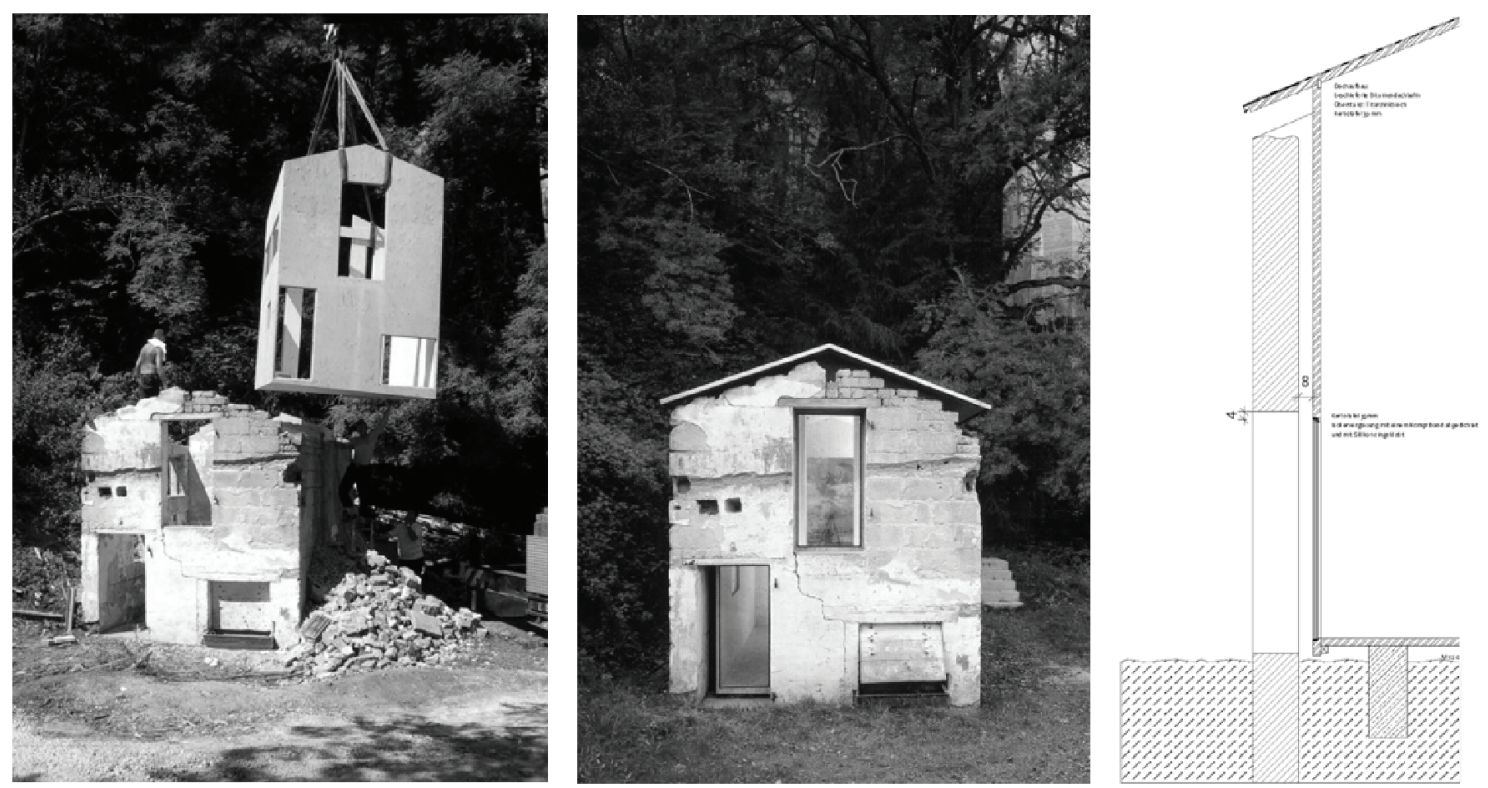

Figure 1. During construction process, final aspect, and constructive section (www.tectonicablog.com).

The previous solution does not actively contribute to stabilize and strengthen the existing construction, only contributing for its preservation through the protection of the new roof plane. A solution designed by Forlani et al. (2012) proposes wooden framed structures to retrofit and rebuild partially destroyed masonry buildings, actively contributing for the consolidation and stabilization of the existing construction. This solution uses wooden systems to make buildings reusable and also to lend them security, see Fig. 2.

The solution consists on few local reparations to consolidate the damaged masonry structures and connect them to the complementary wooden structure that guarantees structural box behavior in case of seismic actions, see Fig. 3a. Through the utilization of trussed elements in all the horizontal panels of each level, in the roof, inside the vertical wooden frames, and by the connection among those horizontal and vertical wooden panels and frames, the designed solution obtains the closed box behavior. Using means of steel plates fixed to the masonry (using steel stirrups), the 3D trussed frame is connected to the masonry walls. A similar connection is used at the roof if the existing walls are standing up with their total original height. The roof provides itself horizontal shear stiffness through a double layer of crossed wooden planking, see Fig. $3 \mathrm{~b}$. In order to reinforce masonry walls for shear actions parallel to their own plane, trussed vertical wooden frames are placed parallel and near to each masonry wall. These trussed wooden frames maintain the masonry walls in their vertical positions.
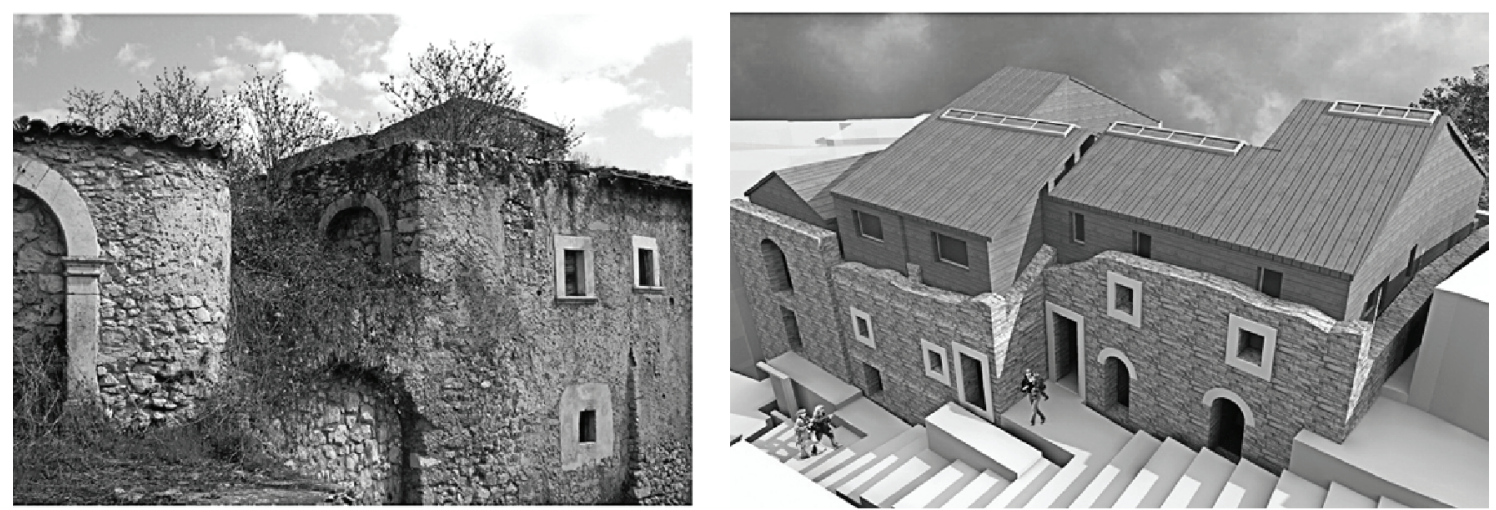

Figure 2. Existing buildings and proposal with the insertion of the wooden volumes (Forlani et al., 2012). 

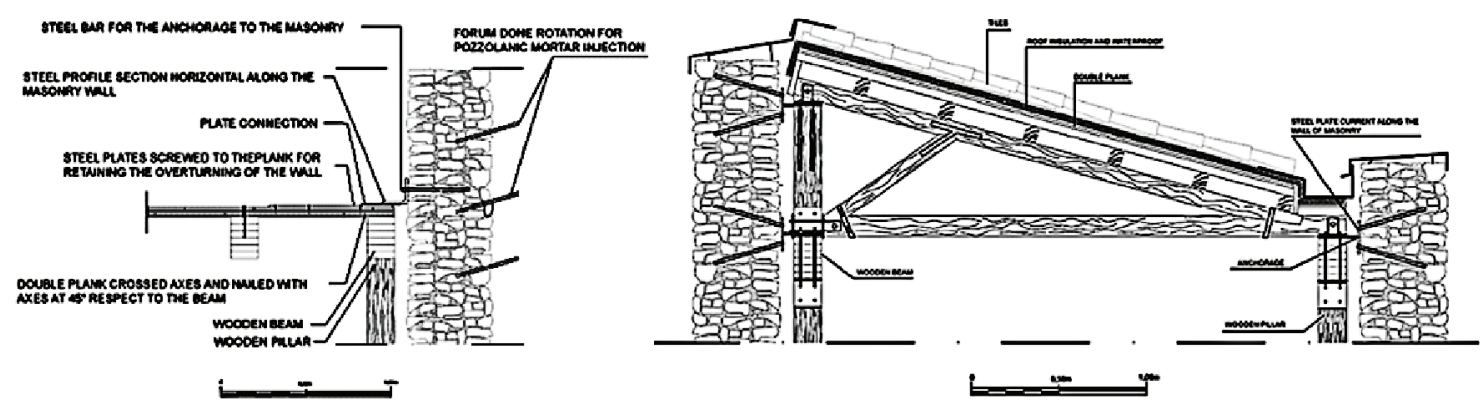

Figure 3a. Connection between a masonry wall and wooden frame at a floor level; Figure 3b. Roof structure connection to the masonry (Forlani et al., 2012).

\subsection{Post-disaster solutions}

The wooden solutions previously presented are preventive actions which aim is to preserve existing constructions and improve their resistance. Wood and wood-based solutions also allow temporary solutions for post-disaster scenarios. After the 2009 L'Aquila earthquake, many cultural heritage buildings were severely damaged or had partially collapsed (Modena et al., 2010; Grimaz, 2011). Provisional works were carried out to avoid damage evolution or buildings' collapse, as well as make them temporarily safe until permanent solutions were being developed and implemented. These provisional works were based mainly on temporary wooden structures, see Fig. 4.

The urgency for fast solutions led the preparation of a field handbook, the Vademecum STOP - schede tecniche delle opere provvisionali per la messa in sicurezza post-sisma da parte dei vigili del fuoco, (Grimaz, 2011). This handbook contains all the information for shoring operations, such as illustrations of the most common design solutions to secure damaged buildings and construction details of connections, joins, anchorages, etc., see Fig. 5.

The handbook aimed to make easy and practical the assessment and sizing of on-site works by the Corpo Nazionale dei Vigili del Fuoco (CNVVF). The standardization of solutions and details definition allowed speeding up the definition on site of the solution to adopt as well as the material needed. The design proposals also considered issues as worker safety, ease and simplicity of handling, timetables, etc. This away, it was possible to realize temporary structures in a faster way, contributing to prevent the propagation of damage as well as provide the damaged structures with stiffness and strength against aftershocks and other phenomena.

The wide range of solutions developed allowed several structural options, making simple and easy the adaptation for the most kind of situations, see Fig. 6.
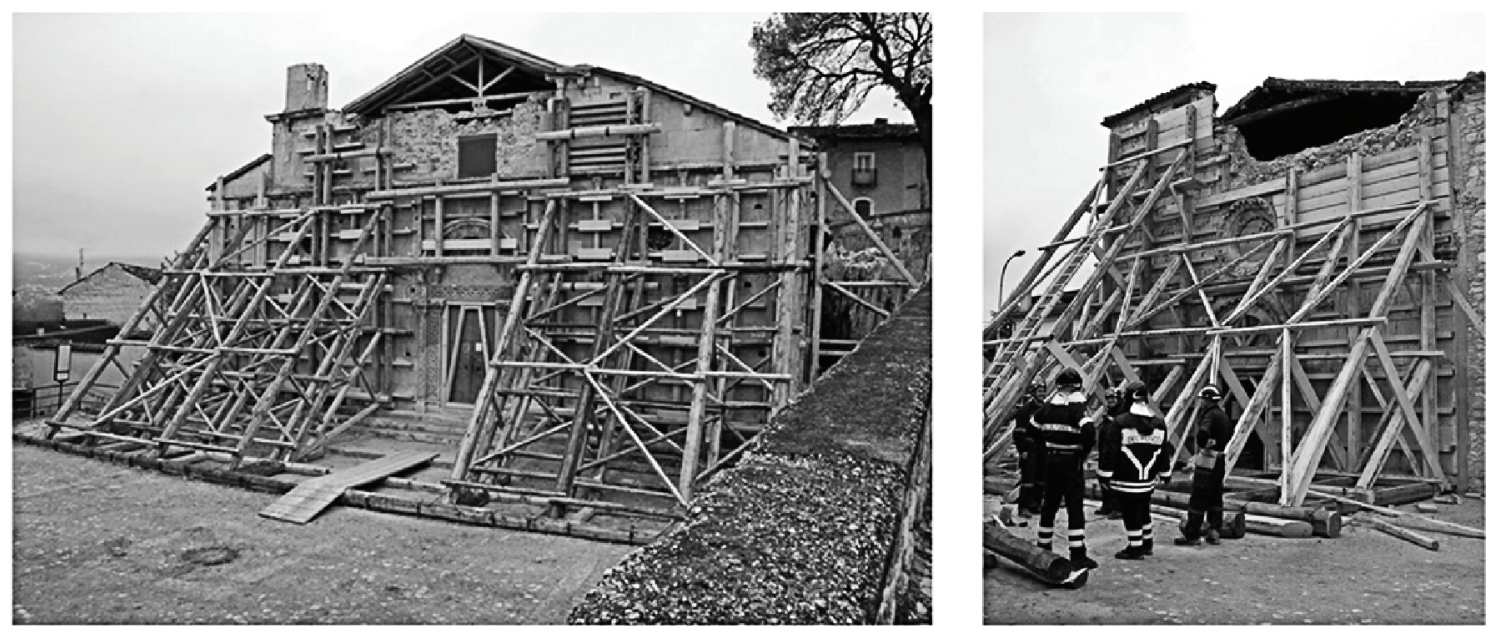

Figure 4. Temporary wooden structures to stop the propagation of damages (www.vigilfuoco.it). 

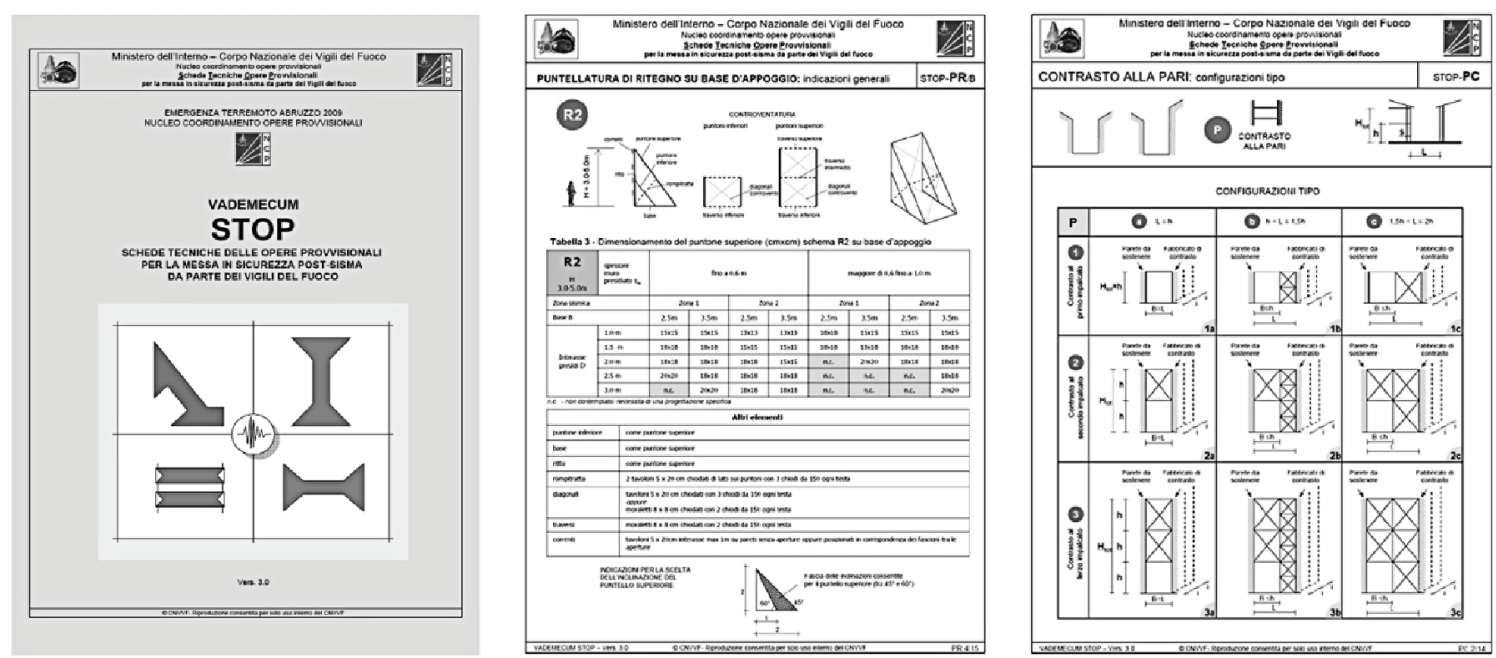

Figure 5. The handbook of STOP: examples of some pages with drawings of temporary solutions (Gruppo di Lavoro NCP, 2010).
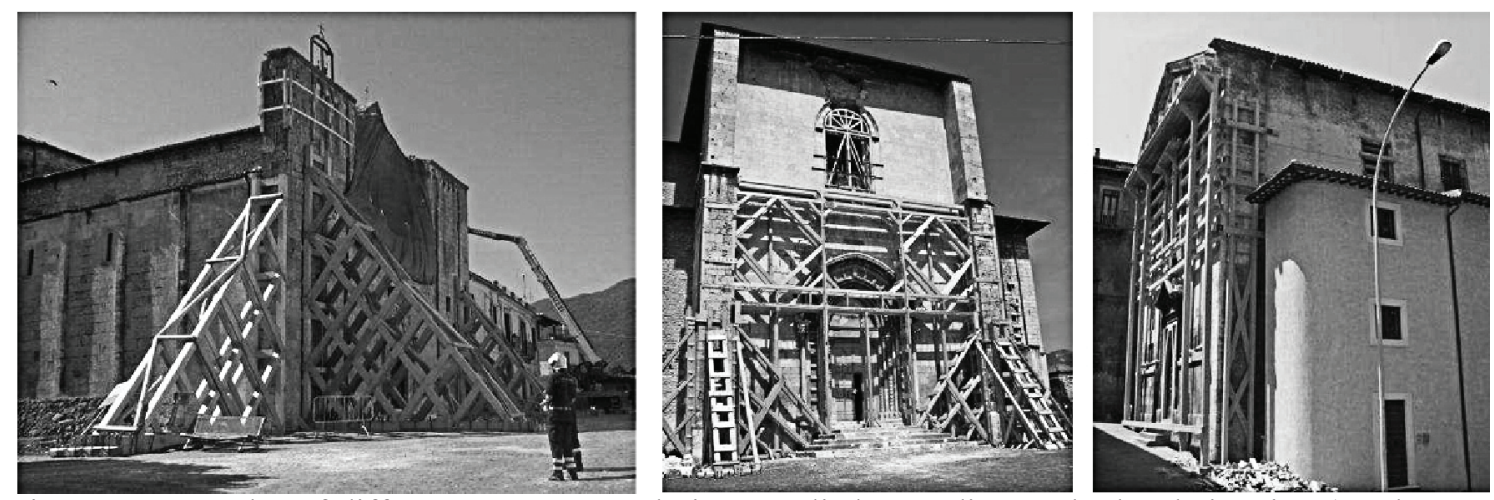

Figure 6. Examples of different temporary solutions applied according to the local situation (Modena et al., 2010).

\section{IMPACT OF THE SOLUTIONS}

Interventions in the built heritage require great responsibility and conscious, something difficult to harmonize with the urgency, complexity and level of pressure after a disaster. It is crucial stopping the propagation of damage, although with adequate interventions that do not neglect buildings' identity and value. Prevention actions are a key to defend historical buildings against degradation and effects of a disaster. Either preservation actions or post-disaster works should preserve the architectural qualities, maintain the original structural scheme and materials, and at the same time being as non-invasive as possible. Moreover, it is extremely important that these solutions do not hinder the execution of future works (Modena et al., 2010). In order to not transform the interventions in irreparable actions, the solutions should be reversible.

Wood and wood-based systems are reversible and allow a rapid solution to prevent the damage's enlargement after a disaster until definitive solutions are developed. After the initial pressure, temporary solutions can be de dismantled and changed by permanent ones. Since the materials are recyclable and reusable, the issues related with the destiny of the first structures' elements are easy to solve.

\section{CONCLUSIONS}

Conserving the heritage without making historic fakes reconstructions or irreparable interventions is an imperative asset to preserve historical centers and historical buildings. After a disas- 
ter, this task becomes even harder as a consequence of the crisis scenario. This study aims to present some examples of interventions with wood and wood-based products that consider the maintenance of the buildings' identity, their original structure scheme and materials, as well as are easily and rapidly built.

Solutions for preventive works that can be realized to strengthen existing damaged constructions, allowing them to be reused and making them more resistant against hazards, have been presented. In the same way, were analyzed temporary wooden solutions that can be applied on a large scale and in a short time to stop the propagation of post-disaster damages. These solutions are crucial to stabilize the damaged buildings while definitive solutions are developed without the pressure of post-disaster crisis. Since these solutions are reversible, they should be a serious possibility to consider, as they allow the protection of the heritage without definitely modify their architectonic identity, value and qualities.

\section{ACKNOWLEDGEMENT}

The first author gratefully acknowledges the financial support of Fundação para a Ciência e a Tecnologia, FCT, through grant SFRH / BD / 73853 / 2010.

\section{REFERENCES}

Alexander, D. 2004. Planning for post-disaster reconstruction. Paper presented in the 2004 International Conference and Student Competition on post-disaster reconstruction "Planning for reconstruction" Coventry, UK, April 22-23, 2004.

Cruz, P.; Pequeno, J. 2008. Timber-Glass Composite Beams: Mechanical Behaviour \& Architectural Solutions, $C G C$, Delft, Holland.

Davidson, C.; Lizarralde, G.; Johnson, C. 2008. Myths and realities of prefabrication for postdisaster reconstruction. Information and Research for Reconstruction. Available at: http://www.resorgs.org.nz/irec2008/i-rec2008_papers.shtml.

Forlani, M. C.; Radogna, D. \& Viskovic, A. 2012. Wooden framed structures for masonry buildings retrofitting. A pilot project in Caporciano. In Jasienko, J. (ed). Proceedings of the International Conference on Structural Analysis of Historical Constructions, SAHC. 15-17 October 2012, Wroclaw, Poland.

Garofalo, L., \& Hill, D. (2008). Prefabricated Recovery: Post-Disaster Housing Component Production and Delivery. Without a Hitch - New Directions in Prefabricated Architecture, (pp. 64 - 71). Massachusetts.

Grimaz, S. 2011. Management of urban shoring during a seismic emergency: advances from the 2009 L'Aquila (Italy) earthquake experience. Bollettino di Geofisica Teorica ed Applicata Vol. 52, n. 2.

Gruppo di Lavoro NCP (Grimaz S. coord.); 2010: Vademecum STOP. Schede tecniche delle opere provvisionali per la messa in sicurezza post-sisma da parte dei Vigili del Fuoco. Corpo Nazionale dei Vigili del Fuoco - Ministero dell'Interno, Roma.

ICOMOS 2004. Recomendações para a análise, conservação e restauro estrutural do património arquitectónico. International Council on Monuments and Sites. Available at www.civil.uminho.pt/masonry.

Jha, Abhas. 2010. Safer Homes, Stronger Communities. A Handbook for Reconstructing after Natural Disasters. The World Bank, Washington DC. Available at: http://www.housingreconstruction.org.

Modena, C.; Porto, F.; Casarin, F.; Munari, M.; Bettiol, G.; Simonato, E. 2010. L'Aquila earthquake: emergency actions for the preservation of Cultural Heritage buildings. Third Euro Mediterranean Symposium on Advances in Geomaterial and Structures. Djerba, Tunisia, 10-12 may, vol. 3, p. 509521.

Modena, C.; Porto, F.; Casarin, F.; Munari, M.; Silva, B.; Bettiol, G.2010. Emergency actions and definitive intervention criteria for the preservation of cultural heritage constructions subjected to seismic actions - Abruzzo 2009. FEUP, Porto.

Ramos, L.; Lourenço, P. B. 2000. Análise das Técnicas de Construção Pombalina e Apreciação do Estado de Conservação Estrutural do Quarteirão do Martinho da Arcada. Engenharia Civil no .7, 35-46.

van de Lindt, J.W. 2008. "Natural Hazards and Wood Construction: The Road to Building Performance." Position paper for the Wood Engineering Challenges in the New Millenium - Critical Research Needs. Proceedings of the Pre-Congress Workshop Offered in Conjunction with the SEI / ASCE Structures Congress 2008, April 23-24, Vancouver, BC, Canada. 